\title{
STUDI ANALISIS Ce(IV) MENGGUNAKAN ASAM TANAT DARI EKSTRAK GAMBIR SECARA SPEKTROFOTOMETRI ULTRAUNGU- TAMPAK
}

\author{
Fergina Prawaning Tyas ${ }^{1}$, R. Supriyanto ${ }^{2}$, dan Ni Luh Ratna Gede Juliasih ${ }^{2}$ \\ ${ }^{1}$ Mahasiswa Jurusan Kimia FMIPA Universitas Lampung \\ ${ }^{2}$ Dosen Jurusan Kimia FMIPA Universitas Lampung \\ ferginatyas@gmail.com
}

Artikel Info
Diterima tanggal
25.08 .2018
Disetujui
publikasi tanggal
30.10.2018
Kata kunci :
asam tanat,
gambir, Ce(IV),
spektrofotometri
ultraungu-
tampak

ABSTRACT

Analysis study of $\mathrm{Ce}(\mathrm{IV})$ using tannic acid from gambier extracts by ultraviolet-visible spectrophotometry was conducted. This study was aim to determine the maximum wavelength at optimum $\mathrm{pH}$, optimum concentration, optimum volume and stability time of complex $\mathrm{Ce}(\mathrm{IV})$-tannic acid extracts gambier. The results showed that the optimum wavelength of complex $\mathrm{Ce}$ (IV)-tannic acid extracts gambier was $520.5 \mathrm{~nm}$ at $\mathrm{pH}$ 11, with stoichiometric ratio of concentration Ce(IV) : tannic acid extracts gambier was $1: 4$, the stoichiometric ratio of volume $\mathrm{Ce}(\mathrm{IV}):$ tannic acid extracts gambier was 1 $: 1$, and the stability time was after 30 minutes. The validation method obtained the r-value of 0.9994 , the LoD and LoQ of 0.027 and 0.090 respectively, the precision of SD 0.0095 and \% RSD of $1.0933 \%$, and the recovery is $89.14 \%$.

\section{PENDAHULUAN}

Serium merupakan salah satu unsur logam transisi golongan III B dalam deretan unsur lantanida, dengan simbol Ce, bersifat lunak dan berwarna abu-abu. Serium digolongkan unsur logam tanah jarang dan termasuk melimpah diantara logam tanah jarang lainnya (Day, 2002). Salah satu metode alternatif untuk menganalisis logam serium dapat dilakukan dengan metode spektrofotometri ultraungutampak. Pada spektrofotometri ultraungu-tampak untuk menganalisis logam secara langsung sulit dilakukan, hal ini disebabkan absorpsivitas molar dari logam cukup kecil untuk dideteksi, sehingga untuk dapat mendeteksi adanya logam serium perlu dilakukan reaksi pembentukan kompleks. Senyawa 
kompleks berasal dari reaksi antara ion logam serium dan ligan yang sesuai, untuk mendapatkan kompleks yang stabil (Anggraeni, et.al., 2016).

Salah satu bahan alam yang dapat digunakan untuk pembentukan kompleks serium adalah asam tanat dari ekstrak gambir. Asam tanat bila ditinjau dari strukturnya merupakan senyawa yang memiliki pasangan elektron bebas, baik pada gugus keton (pada keadaan polimer) dan gugus hidroksil (ketika ditambahkan basa atau asam pada saat pengaturan $\mathrm{pH}$ ). Pasangan elektron ini dapat didonorkan kepada ion logam serium yang memiliki orbital kosong, sehingga asam tanat merupakan suatu ligan yang mendonorkan pasangan elektron bebasnya kepada logam serium untuk membentuk suatu senyawa kompleks serium (Supriyanto, 2011).

Pada penelitian ini dilakukan analisis Ce(IV) dengan metode spektrofotometri ultraungutampak dengan memanfaatkan ligan alam yaitu asam tanat dari ekstrak gambir sebagai pengompleksnya. Penelitian ini dilakukan untuk memperoleh kondisi optimum pembentukan kompleks Ce(IV)-asam tanat ekstrak gambir, diantaranya pengaruh $\mathrm{pH}$, perbandingan konsentrasi, perbandingan volume, dan waktu untuk mencapai kestabilan kompleks.

\section{METODE}

\section{Alat dan Bahan}

Alat utama yang digunakan dalam penelitian ini adalah alat gelas yang umum digunakan di laboratorium, neraca analitik (AND.HR-150A), pH meter (Metrohm 827), pipet volume, mikropipet (Joanlab 100-1000 $\mu \mathrm{L}$ ), batang pengaduk, spatula, dan spektrofotometer ultraungu-tampak (Hitachi U-2010). Bahan yang adalah asam tanat dari ekstrak gambir, $\mathrm{Ce}\left(\mathrm{SO}_{4}\right)_{2} .5 \mathrm{H}_{2} \mathrm{O}$ pro-analisis, larutan $\mathrm{NaOH}$, akuabides, dan akuades.

\section{Prosedur}

\section{Pembuatan Larutan Stok Asam Tanat Ekstrak Gambir dan Ce(IV) 100 mM}

Ditimbang 17,012 gram asam tanat ekstrak gambir dan 4,221 gram $\mathrm{Ce}\left(\mathrm{SO}_{4}\right)_{2} .5 \mathrm{H}_{2} \mathrm{O}$ menggunakan neraca analitik, kemudian dilarutkan menggunakan akuabides di dalam labu takar $100 \mathrm{ml}$ hingga tanda batas dan dihomogenkan.

\section{Optimasi Panjang Gelombang Maksimum pada Ion Logam Cd(II) dan Asam Tanat Ekstrak Gambir}

Penentuan panjang gelombang optimum pada masing-masing larutan induk, yaitu Ce(IV) dan asam tanat ekstrak gambir dengan menggunakan larutan stok $100 \mathrm{mM}$ yang 
diencerkan menjadi $1 \mathrm{mM}$. Panjang gelombang maksimum kemudian diukur dengan spektrofotometer ultraungu-tampak.

\section{Penentuan pH Optimum Pembentukan Kompleks Ce(IV)-Asam Tanat Ekstrak Gambir}

Penentuan $\mathrm{pH}$ optimum dilakukan dengan cara mereaksikan Ce(IV) $1 \mathrm{mM}$ dengan asam tanat ekstrak gambir $1 \mathrm{mM}$ pada $\mathrm{pH} 8,9,10,11$, dan 12. Optimasi ini dilakukan dengan menggunakan spektrofotometer ultraungu-tampak.

\section{Penentuan Stoikiometri Pembentukan Kompleks Ce(IV)-Asam Tanat Ekstrak Gambir Variasi Konsentrasi Asam Tanat Ekstrak Gambir (mM)}

Penentuan ini dilakukan dengan cara mengukur absorbansi kompleks Ce(IV)-asam tanat ekstrak gambir pada $\mathrm{pH}$ optimum dan panjang gelombang optimum dengan perbandingan konsentrasi logam $\mathrm{Ce}(\mathrm{IV})$ : asam tanat ekstrak gambir yaitu 1:1, 1:2, 1:3, 1:4, dan 1:5 menggunakan spektrofotometer ultraungu-tampak.

\section{Variasi Konsentrasi Ion Logam Serium (mM)}

Penentuan ini dilakukan dengan cara mengukur absorbansi kompleks Ce(IV)-asam tanat ekstrak gambir pada $\mathrm{pH}$ optimum dan panjang gelombang optimum dengan perbandingan konsentrasi logam $\mathrm{Ce}(\mathrm{IV})$ : asam tanat ekstrak gambir yaitu 1:1, 2:1, 3:1, 4:1, dan 5:1 menggunakan spektrofotometer ultraungu-tampak.

\section{Variasi Volume Ion Logam Serium (mL)}

Penentuan dilakukan dengan cara mengukur absorbansi kompleks Ce(IV)-asam tanat ekstrak gambir pada $\mathrm{pH}$ optimum, konsentrasi optimum dan panjang gelombang optimum, lalu memvariasikan volume logam $\mathrm{Ce}(\mathrm{IV})$ dengan perbandingan $\mathrm{Ce}(\mathrm{IV})$ : asam tanat ekstrak gambir 1:1, 2:1, 3:1, 4:1, dan 5:1 menggunakan spektrofotometer ultraungu-tampak.

\section{Variasi Volume Asam Tanat Ekstrak Gambir (mL)}

Penentuan dilakukan dengan cara mengukur absorbansi kompleks Ce(IV)-asam tanat ekstrak gambir pada $\mathrm{pH}$ optimum, konsentrasi optimum dan panjang gelombang optimum, lalu memvariasikan volume asam tanat ekstrak gambir dengan perbandingan $\mathrm{Ce}(\mathrm{IV})$ : asam tanat ekstrak gambir 1:1, 1:2, 1:3, 1:4 dan 1:5 menggunakan spektrofotometer ultraungu-tampak.

Penentuan Waktu Kestabilan Pembentukan Kompleks Ce(IV)-Asam Tanat Ekstrak Gambir 
Penentuan waktu kestabilan kompleks dilakukan dengan perbandingan konsentrasi terbaik yang diperoleh, diukur absorbansinya dengan menggunakan spektrofotometer ultraungutampak pada panjang gelombang optimum dan $\mathrm{pH}$ optimum dari 0 menit sampai 60 menit dengan skala kenaikan 10 menit.

\section{Validasi Metode}

\section{Linearitas}

Penentuan linearitas dilakukan dengan membuat larutan Ce(IV) dengan konsentrasi yang berbeda yaitu 1, 3, 5, 7, dan $9 \mathrm{mM}$, kemudian ditambahkan larutan asam tanat ekstrak gambir dengan konsentrasi optimum. Masing-masing larutan kompleks diukur absorbansinya menggunakan spektrofotometer ultraungu-tampak. Nilai absorbansi yang diperoleh dibuat persamaan linear hubungan antara konsentrasi dengan absorbansi. Nilai $r$ yang diperoleh menggambarkan linearitas.

\section{Penentuan Limit Deteksi (LoD) dan Limit Kuantifikasi (LoQ)}

Limit deteksi dilakukan dengan cara larutan blanko (tanpa analit) diberi perlakuan yang sama seperti sampel, kemudian diukur absorbansinya dengan menggunakan spektrofotometer ultaungu-tampak. Nilai LoD dan LoQ kemudian dihitung dengan persamaan :

$$
L o D=\frac{3,3 S_{y / x}}{b} \quad L o Q=\frac{10 S_{y / x}}{b}
$$

\section{Penentuan Akurasi}

Penentuan nilai akurasi dilakukan dengan menambahkan sejumlah analit murni ke dalam campuran (air kran yang telah ditambahkan logam Ce(IV) yang diketahui kadarnya). Kemudian campuran dianalisis dan hasilnya dibandingkan terhadap kadar analit yang ditambahkan (kadar sebenarnya). Jumlah analit yang ditambahkan ke dalam sampel atau selisih antara rata-rata dan nillai sebenarnya yang didapat menunjukan ketepatan. Ketepatan dihitung dengan \% recovery (perolehan kembali).

\section{Penentuan Presisi}

Penentuan nilai presisi ditentukan dengan mengukur konsentrasi sampel dengan 6 kali pengulangan. Nilai absorbansi yang telah diperoleh ditentukan simpangan baku (SD) serta nilai 
relatif standar deviasi (RSD). Metode dengan presisi yang baik ditunjukan dengan perolehan nilai \% RSD < $5 \%$ (Cristian, 1986).

\section{HASIL DAN PEMBAHASAN}

\section{Penentuan Panjang Gelombang Maksimum Ion Logam Ce(IV) dan Asam Tanat Ekstrak Gambir}

Penentuan panjang gelombang maksimum menggunakan spektrofotometer ultraungutampak dilakukan pada rentang panjang gelombang 200 - $300 \mathrm{~nm}$ untuk logam Ce(IV) dan 250 $300 \mathrm{~nm}$ untuk asam tanat ekstrak gambir.

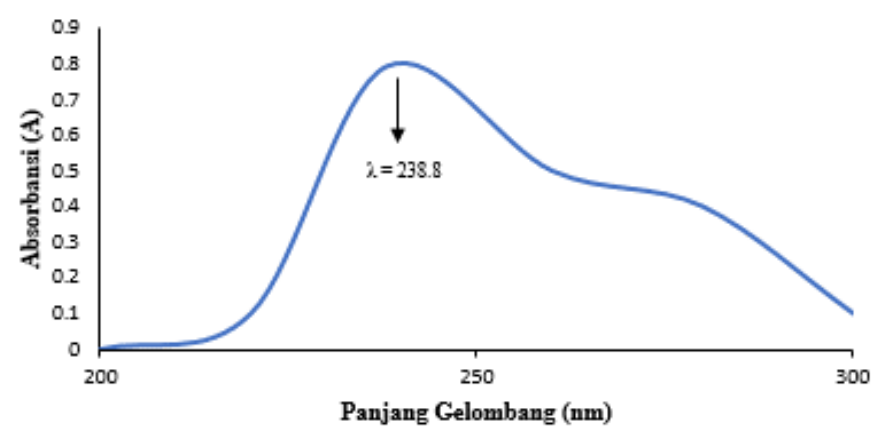

a

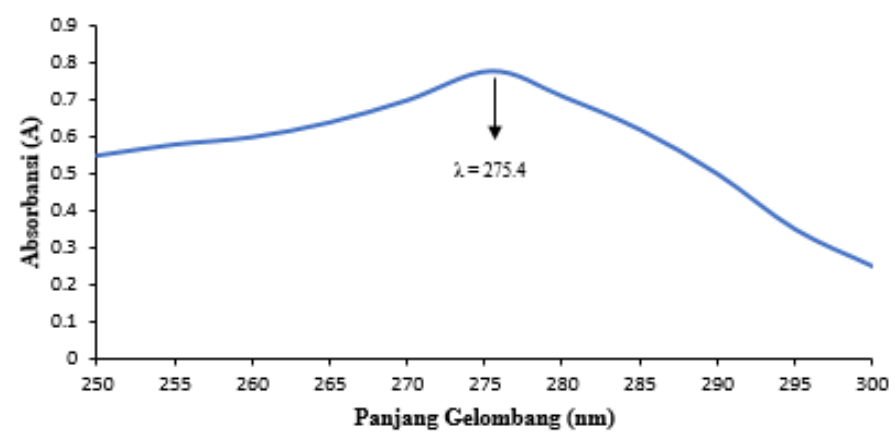

b

Gambar 1. Kurva Panjang Gelombang Maksimum (a) Logam Ce(IV) dan (b) Asam Tanat Ekstrak Gambir

Berdasarkan Gambar 1 dapat dilihat bahwa panjang gelombang maksimumm logam $\mathrm{Ce}(\mathrm{IV})$ sebesar 238,8 nm. Panjang gelombang maksimum asam tanat ekstrak gambir sebesar $275,4 \mathrm{~nm}$, angka ini menunjukkan nilai panjanng gelombang yang tidak jauh berbeda dengan 
penelitian Andriani (2011), yang menyatakan panjang gelombang asam tanat standar sebesar $257,6 \mathrm{~nm}$.

\section{Pengaruh Variasi pH pada Pembentukam Kompleks Ce(IV)-Asam Tanat Ekstrak Gambir}

Penentuan ini dilakukan dengan cara pengaturan $\mathrm{pH}$ antara logam $\mathrm{Ce}(\mathrm{IV})$ dengan asam tanat ekstrak gambir yang divariasikan dengan penambahan larutan $\mathrm{NaOH}$ dari $\mathrm{pH} 8$ sampai 12 dengan skala kenaikan $\mathrm{pH} 1$.

Tabel 1. Pengaruh $\mathrm{pH}$ terhadap absorbansi dan panjang gelombang kompleks $\mathrm{Ce}(\mathrm{IV})$ asam tanat ekstrak gambir

\begin{tabular}{ccc}
\hline $\mathbf{p H}$ & Absorbansi & Panjang Gelombang \\
\hline 8 & 0.503 & 419.5 \\
9 & 0.671 & 437.0 \\
10 & 0.776 & 485.0 \\
11 & 0.798 & 520.5 \\
\hline
\end{tabular}

Berdasarkan data pada Tabel 1 dapat dibuat kurva hubungan antara absorbansi dengan perubahan $\mathrm{pH}$ antara Ce(IV)-asam tanat ekstrak gambir, ditunjukkan pada Gambar 2.

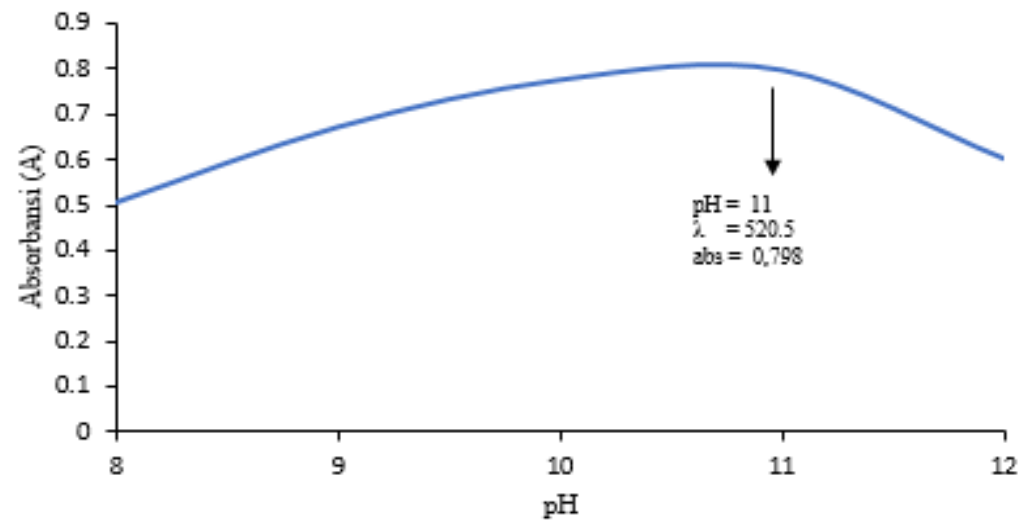

Gambar 2. Kurva hubungan antara pH optimum dengan absorbansi kompleks Ce(IV)-asam tanat ekstrak gambir

Berdasarkan hasil yang didapat, $\mathrm{pH}$ optimum untuk kompleks Ce(IV)-asam tanat ekstrak gambir adalah pada $\mathrm{pH}$ 11, pada panjang gelombang 520,5 nm. Hal ini menunjukkan bahwa asam tanat yang diatur $\mathrm{pH}$ di atas 8 akan terhidrolisis menjadi monomer asam galat. Menurut Supriyanto (2011), asam tanat dari ekstrak gambir dapat bereaksi membentuk senyawa 
kompleks dengan logam apabila $\mathrm{pH}$ di atas 8 dalam bentuk asam galat, sehingga asam galat akan lebih mudah mendonorkan pasangan elektron bebas kepada logam Ce(IV) untuk membentuk senyawa kompleks.

\section{Penentuan Stoikiometri Kompleks Ce(IV)-Asam Tanat Ekstrak Gambir dengan Variasi Konsentrasi}

Larutan logam Ce(IV) dengan variasi konsentrasi 1, 2, 3, 4, dan $5 \mathrm{mM}$ ditambahkan ke dalam asam tanat ekstrak gambir $1 \mathrm{mM}$ yang diencerkan dari larutan stok $10 \mathrm{mM}$ pada $\mathrm{pH} 11$, kemudian diukur pada panjang gelombang $520,5 \mathrm{~nm}$.

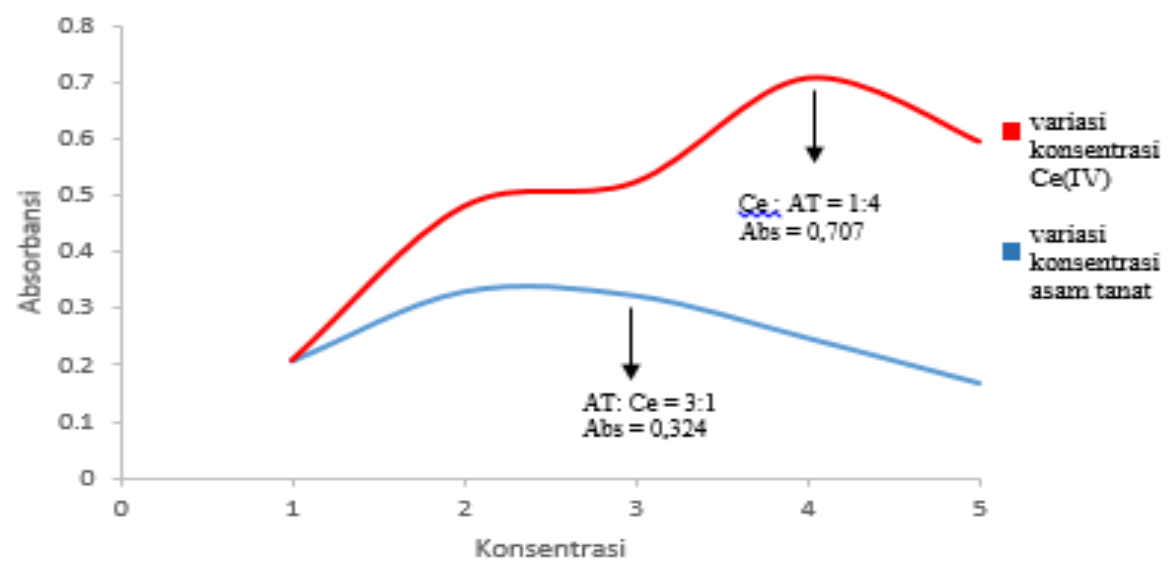

Gambar 3. Kurva hubungan antara konsentrasi kompleks Ce(IV)-asam tanat ekstrak gambir dengan absorbansi

Absorbansi optimum kompleks yaitu pada perbandingan konsentrasi antara Ce(IV) : asam tanat ekstrak gambir yaitu $1: 4$. Hal ini menunjukkan bahwa pada variasi konsentrasi tersebut diperoleh kompleks yang jenuh, dimana ligan mendonorkan pasangan elektron bebasnya pada logam, sehingga membentuk ikatan kovalen koordinasi. Ce(IV) berperan sebagai ion pusat, dan berikatan dengan 4 elektron bebas dari asam tanat yang berperan sebagai ligan, sehingga diperkirakan struktur kompleks Ce(IV)-asam tanat ekstrak gambir yang terbentuk seperti pada Gambar 4.<smiles></smiles>

Gambar 4. Struktur dugaan kompleks Ce(IV)-asam tanat ekstrak gambir (Masoud et.al., 2012) 


\section{Penentuan Stoikiometri Kompleks Ce(IV)-Asam Tanat Ekstrak Gambir dengan Variasi Volume}

Larutan $\mathrm{Ce}(\mathrm{IV})$ dan asam tanat ekstrak gambir dengan konsentrasi masing-masing 1 $\mathrm{mM}$ dan $4 \mathrm{mM}$ yang diencerkan dari larutan $10 \mathrm{mM}$ pada $\mathrm{pH} 11$ divariasikan volumenya masing-masing 1 sampai $5 \mathrm{~mL}$ dan diukur pada panjang gelombang $520,5 \mathrm{~nm}$.

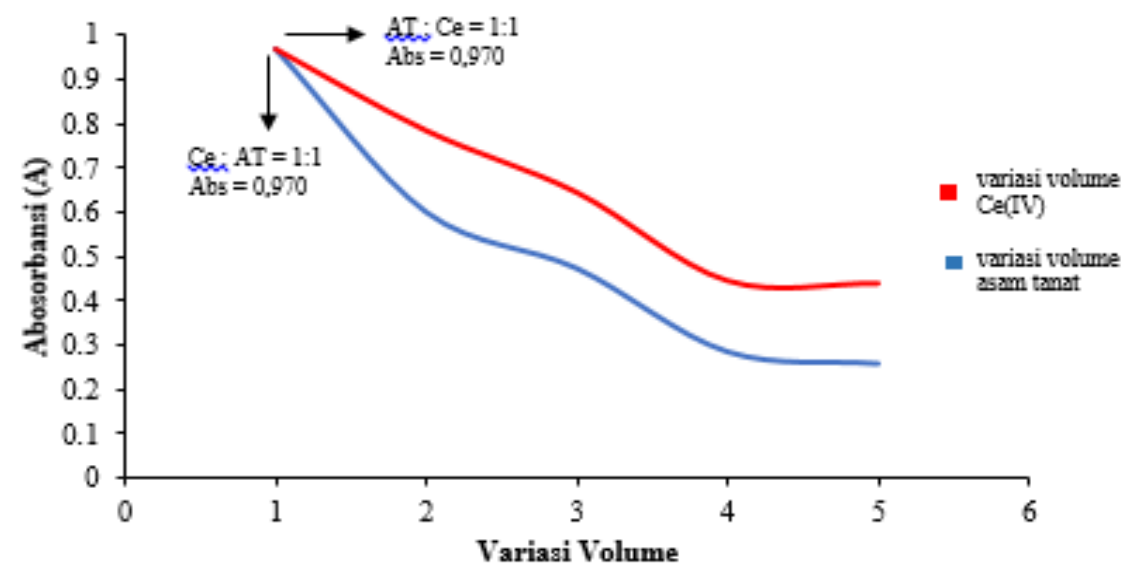

Gambar 5. Kurva hubungan variasi volume kompleks Ce(IV)-asam tanat ekstrak gambir dengan absorbansi

Berdasarkan Gambar 5 absorbansi optimum ditunjukan pada perbandingan volume Ce(IV) : asam tanat ekstrak gambir yaitu 1:1 dengan absorbansi sebesar 0,970. Hasil yang diperoleh pada variasi volume tersebut menunjukkan komposisi yang tepat untuk membentuk senyawa kompleks Ce(IV)-asam tanat.

\section{Penentuan Waktu Kestabilan Kompleks Ce(IV)-Asam Tanat Ekstrak Gambir}

Penentuan waktu kestabilan kompleks Ce(IV)-asam tanat ekstrak gambir dilakukan pada $\mathrm{pH}$ 11, perbandingan stoikiometri konsentrasi 1:4, perbandingan stoikiometri volume 1:1 yang diukur pada panjang gelombang 520,5 nm, setiap 10 menit pada rentang waktu 0-60 menit. 


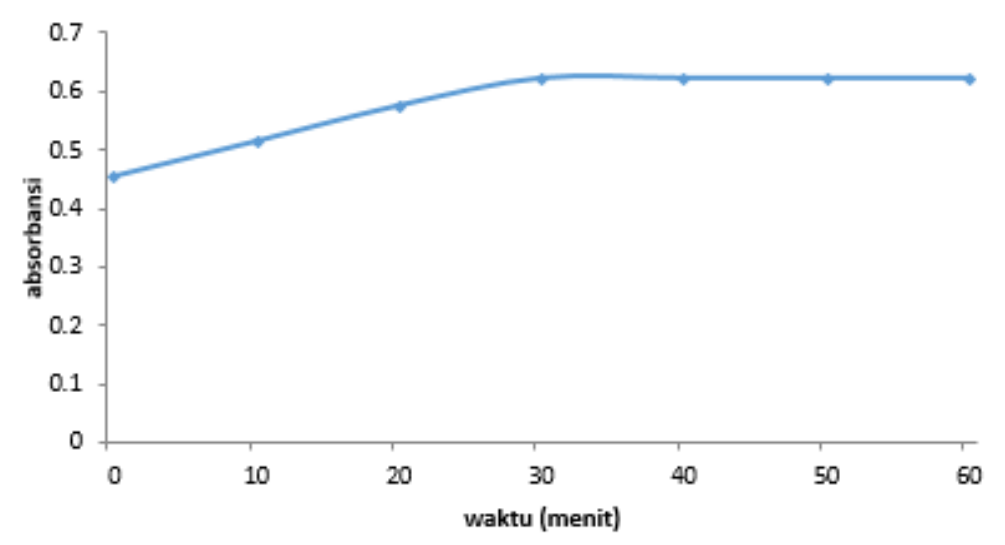

Gambar 6. Kurva hubungan antara waktu pembentukan kompleks Ce(IV)-asam tanat ekstrak gambir dengan absorbansi

Kurva pada Gambar 6 menunjukkan bahwa kompleks Ce(IV)-asam tanat ekstrak gambir mengalami kestabilan setelah menit ke 30 dengan absorbansi sebesar 0,622.

\section{Validasi Metode: Linearitas}

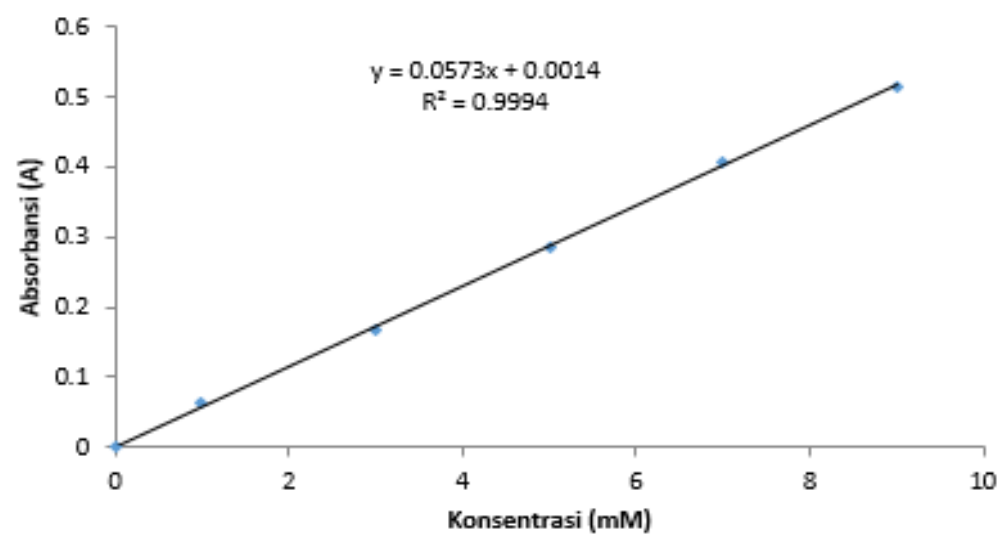

Gambar 17. Kurva linearitas kompleks Ce(IV)-asam tanat ekstrak gambir

\section{Limit Deteksi (LoD) dan Limit Kuantifikasi (LoQ)}

Nilai LoD dan LoQ pada analisis kompleks Ce(IV)-asam tanat ekstrak gambir berturutturut sebesar 0,027 dan 0,090. Hal ini menunjukan bahwa metode yang digunakan dalam penelitian ini mampu memberikan respon untuk analisis logam dengan jumlah analit yang sangat kecil dan mampu memberikan respon dengan nilai akurasi dan presisi yang dapat diterima dalam analisis. 


\title{
Presisi (Ketelitian)
}

Tabel 3. Hasil pengukuran uji presisi kompleks Ce(IV)-asam tanat ekstrak gambir

\begin{tabular}{ccc}
\hline Pengulangan & Absorbansi & Konsentrasi Terukur \\
\hline 1 & 0,052 & 0,8831 \\
2 & 0,051 & 0,8656 \\
3 & 0,051 & 0,8656 \\
4 & 0,052 & 0,8831 \\
5 & 0,052 & 0,8831 \\
6 & 0,052 & 0,8831 \\
\hline & Rata-rata & 0,8743 \\
& SD & 0,0095 \\
& \%RD & 1,0933 \\
\hline
\end{tabular}

Menurut Cristian (1986) nilai RSD yang baik adalah <5\% untuk tingkat kepercayaan 95\%. Berdasarkan nilai simpangan baku (SD) dan simpangan baku relatif (RSD) yang diperoleh pada penelitian ini dapat dikatakan tergolong baik untuk metode uji analisis logam Ce(IV).

\begin{abstract}
Akurasi
Nilai \% recovery yang dihasilkan pada analisis logam Ce(IV) adalah sebesar 89,14\%. Menurut AOAC (2002), rentang \% recovery yang baik berkisar 75-120\% untuk satuan konsentrasi 1 ppm, sehingga nilai \% recovery untuk metode uji analisis logam Ce(IV) pada penelitian ini dapat dikatakan tergolong baik.
\end{abstract}

\section{KESIMPULAN}

Panjang gelombang maksimum asam tanat ekstrak gambir dengan konsentrasi $1 \mathrm{mM}$ diperoleh pada 275,4 nm, sedangkan panjang gelombang maksimum Ce(IV) dengan konsentrasi $1 \mathrm{mM}$ diperoleh pada 238,8 nm. Kondisi optimum kompleks Ce(IV)-asam tanat ekstrak gambir diperoleh pada panjang gelombang 520,5 nm, dengan $\mathrm{pH}$ optimum 11, perbandingan stoikiometri konsentrasi 1:4 (Ce(IV) : asam tanat ekstrak gambir), perbandingan stoikiometri volume 1:1 (Ce(IV) : asam tanat ekstrak gambir), setelah menit ke 30. Validasi metode pembentukan kompleks Ce(IV) - asam tanat ekstrak gambir diperoleh nilai r sebesar 0,9994, nilai LoD dan LoQ yang diperoleh sebesar 0,027 dan 0,090, uji pesisi dengan nilai SD 0,0095 dan \% RSD sebesar $1,0933 \%$, serta nilai \% recovery yang diperoleh yaitu $89,14 \%$. 


\section{DAFTAR PUSTAKA}

Andriani, M. 2011. Skripsi: Studi Analisis Spesiasi Ion Logam Cr(III) dan Cr(VI) dengan Asam Tanat dari Ekstrak Gambir Menggunakan Spektrofotometri Ultaungu-Tampak. Universitas Lampung. Bandar Lampung.

Anggraeni, A., Sofyatin, T., Fauzia, R.P. dan Bahti, H.H. 2016. Ekstraksi Samarium(III) dan Serium (IV) Melalui Pembentukan Kompleks Menggunakan Ligan

Etilendiamintetrametilenfosfonat. Departemen Kimia-FMIPA Universitas Padjajaran. Bandung.

AOAC. 2002. Guidelines for Single Laboratory Validation of Chemical Methods for Dietary Supplements and Botanicals. AOAC International. Gaithersburg.

Cristian, G.D. 1986. Analytical Chemistry; Fourth Edition. John Wiley and Sons Inc. University of Washington.

Day, R.A. dan Underwood, A.L. 2002. Analisis Kimia Kuantitatif Edisi Keenam. Erlangga. Jakarta.

Masoud, M.S., Hagagg, S.S., Ali, A.E., dan Nasr, N.M. 2012. Synthesis and Spectroscopic Characterization of Gallic Acid and Some of its Azo Coplexes. Journal of Molecular Structure. 1014(2012):17-25.

Supriyanto, R. 2011. Studi Analisis Spesiasi Ion Logam Cr(III) dan Cr(VI) dengan Asam Tanat dari Ekstrak Gaambir menggunakan Spektrometri Uv-Vis. Jurnal Sains MIPA. 17(1) : 3542. 